\title{
Comparison of UV irradiances from Aura/Ozone Monitoring Instrument (OMI) with Brewer measurements at El Arenosillo (Spain) - Part 1: Analysis of parameter influence
}

\author{
M. Antón ${ }^{1, *}$, V. E. Cachorro ${ }^{2}$, J. M. Vilaplana ${ }^{3}$, C. Toledano ${ }^{2}$, N. A. Krotkov ${ }^{4,6}$, A. Arola ${ }^{5}$, A. Serrano ${ }^{1}$, and \\ B. de la Morena ${ }^{3}$ \\ ${ }^{1}$ Departamento de Física, Universidad de Extremadura, Badajoz, Spain \\ ${ }^{2}$ Grupo de Óptica Atmosférica, Universidad de Valladolid GOA-UVA, Valladolid, Spain \\ ${ }^{3}$ ESAt "El Arenosillo", INTA, Huelva, Spain \\ ${ }^{4}$ GEST Center, University of Maryland, Baltimore County, Maryland, USA \\ ${ }^{5}$ Finnish Meteorological Institute (FMI), Kuopio, Finland \\ ${ }^{6}$ Laboratory of Atmosphere, NASA/Goddard Space Flight Center, Greenbelt, Maryland, USA \\ * now at: Departamento de Física Aplicada, Universidad de Granada, Granada, Spain
}

Received: 9 February 2010 - Published in Atmos. Chem. Phys. Discuss.: 11 March 2010

Revised: 25 May 2010 - Accepted: 16 June 2010 - Published: 5 July 2010

\begin{abstract}
The main objective of this study is to compare the erythemal UV irradiance (UVER) and spectral UV irradiances (at 305, 310 and $324 \mathrm{~nm}$ ) from the Ozone Monitoring Instrument (OMI) onboard NASA EOS/Aura polar sun-synchronous satellite (launched in July 2004, local equator crossing time 01:45 p.m.) with ground-based measurements from the Brewer spectrophotometer \#150 located at El Arenosillo (South of Spain). The analyzed period comprises more than four years, from October 2004 to December 2008. The effects of several factors (clouds, aerosols and the solar elevation) on OMI-Brewer comparisons were analyzed. The proxies used for each factor were: OMI Lambertian Equivalent Reflectivity (LER) at $360 \mathrm{~nm}$ (clouds), the aerosol optical depth (AOD) at $440 \mathrm{~nm}$ measured from the ground-based Cimel sun-photometer (http://aeronet.gsfc.nasa.gov), and solar zenith angle (SZA) at OMI overpass time. The comparison for all sky conditions reveals positive biases (OMI higher than Brewer) $12.3 \%$ for UVER, $14.2 \%$ for UV irradiance at $305 \mathrm{~nm}, 10.6 \%$ for $310 \mathrm{~nm}$ and $8.7 \%$ for $324 \mathrm{~nm}$. The OMI-Brewer root mean square error (RMSE) is reduced when cloudy cases are removed from the analysis, (e.g., RMSE $\sim 20 \%$ for all sky conditions and RMSE smaller than
\end{abstract}

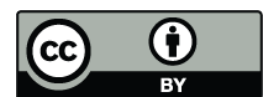

Correspondence to: V. E. Cachorro (chiqui@goa.uva.es)
$10 \%$ for cloud-free conditions). However, the biases remain and even become more significant for the cloud-free cases with respect to all sky conditions. The mentioned overestimation is partially due to aerosol extinction influence. In addition, the differences OMI-Brewer typically decrease with SZA except days with high aerosol loading, when the bias is near constant. The seasonal dependence of the OMI-Brewer difference for cloud-free conditions is driven by aerosol climatology.

To account for the aerosol effect, a first evaluation in order to compare with previous TOMS results (Antón et al., 2007) was performed. This comparison shows that the OMI bias is between $+14 \%$ and $+19 \%$ for UVER and spectral UV irradiances for moderately-high aerosol load $(\mathrm{AOD}>0.25)$. The OMI bias is decreased by a factor of 2 (the typical bias varies from $+8 \%$ to $+12 \%$ ) under cloud-free and low aerosol load conditions $(\mathrm{AOD}<0.1)$. More detailed analysis of absorbing aerosols influence on OMI bias at our station is presented in a companion paper (Cachorro et al., 2010).

\section{Introduction}

The study of ultraviolet (UV) solar radiation reaching the Earth's surface has achieved a notable interest in the last decades. This is due to concerns related to the well-known

Published by Copernicus Publications on behalf of the European Geosciences Union. 
ozone depletion (WMO, 2006). Thus, it is of great importance to continue high accuracy UV radiation measurements at different locations. Satellite UV data complement groundbased measurements providing global daily maps with uniform geographical coverage from a single instrument. The continuous validation of satellite UV data with ground-based measurements from well-calibrated and well-maintained instruments is an essential task for assessing the quality and accuracy of satellite data and to identify local to regional specific sources of uncertainty (e.g., Arola et al., 2005; Tanskanen et al., 2007).

Ozone Monitoring Instrument (OMI) (Levelt et al., 2006), launched in July 2004, is the successor to the Total Ozone Mapping Spectrometer (TOMS) instruments. In the last decade, the UV irradiance products from TOMS has been extensively compared with ground measurements mostly using Brewer spectrophotometers (Kalliskota et al., 2000; McKenzie et al., 2001; Chubarova et al., 2002; Sabburg et al., 2002; Fioletov et al., 2004; Cede et al., 2004; Meloni et al., 2005; Arola et al., 2005; Kazantzidis et al., 2006). These works revealed that the satellite UV data overestimate the ground-based measurements in many locations. The work of Antón et al. (2007) compared the erythemal UV irradiance (UVER) derived from TOMS with Brewer measurements at El Arenosillo (South Spain) under different sky conditions. This work showed that TOMS overestimates the UVER data by $12 \%$ during cloud-free days, and the bias increases with the aerosol load.

The first comprehensive validation of the OMI UV products can be found in Tanskanen et al. (2007), which shows good agreement between OMI-derived daily erythermal doses and the daily doses calculated from the groundbased spectral UV measurements from 18 reference stations in Europe, Canada, Japan, USA and Antarctic. However, for OMI the bias increased up to $50 \%$ for sites affected by absorbing aerosols or trace gases. In addition, Buchard et al. (2008) compared the UV irradiance products from OMI with ground-based measurements recorded at two French locations, showing that the bias is less than $15 \%$ for clear sky conditions. Ialongo et al. (2008) showed that OMI UV data overestimate ground-based UVER values measured from both Brewer spectrophotometer and YES broadband radiometer (biases about 20\%) at Rome (Italy). Weihs et al. (2008) showed that OMI-Brewer differences can reach $+50 \%$ under overcast conditions during a validation campaign in the region of Vienna (Austria). Kazadzis et al. (2009) compared UV irradiance products from OMI against ground-based Brewer measurements at Thessaloniki (Greece), showing that OMI overestimates UV spectral irradiances by $30 \%, 17 \%$ and $13 \%$ for $305 \mathrm{~nm}, 324 \mathrm{~nm}$, and $380 \mathrm{~nm}$, respectively.

Within this framework, this paper aims to compare UV irradiances derived from OMI (collection 3) with UV irradiances measured by the Brewer spectrophotometer \#150 located at El Arenosillo. The period of study extends from
October 2004 to December 2008. The effects of clouds and aerosols on the OMI-Brewer UV differences are analyzed in detail. El Arenosillo station is an ideal location for OMI validation studies because of its high number of cloud-free days per year and the moderate frequency of desert dust outbreaks from Africa (Toledano et al., 2007a).

The paper is organized as follows. The ground and satellite-based measurements are described in Sect. 2. Section 3 introduces the methodology. The results and discussion are presented in Sect. 4 and, finally, Sect. 5 summarizes main conclusions.

\section{Data}

\subsection{Satellite observations}

The OMI satellite instrument is a contribution of the Netherlands' Agency for Aerospace Programs (NIVR) in collaboration with the Finnish Meteorological Institute (FMI). It is on board the NASA EOS/Aura platform launched in July 2004 (Schoeberl et al., 2006). This remote sensing UV spectrometer continues currently long-term ozone measurements by NASA Total Ozone Mapping Spectrometer (TOMS) instrument which was operative on board of two satellites: Nimbus-7 (1978-1993) and Earth Probe (EP) (1996-2005). The OMI instrument is a nadir viewing spectrometer that measures solar reflected and backscattered radiation in the wavelength range from $270 \mathrm{~nm}$ to $500 \mathrm{~nm}$ with a spectral resolution of $0.55 \mathrm{~nm}$ in the ultraviolet and $0.63 \mathrm{~nm}$ in the visible. The instrument has a $2600 \mathrm{~km}$ wide viewing swath and it is capable of daily global contiguous mapping.

The OMI surface UV algorithm (OMUVB) is based on the TOMS UV algorithm developed at NASA Goddard Space Flight Center (GSFC) (Krotkov et al., 1998, 2001). This algorithm estimates the surface UV irradiance from lookup tables (LUTs) obtained by a radiative transfer model using the OMI-derived total ozone, surface albedo and cloud information as input parameters for modelling (Tanskanen et al., 2006, 2007).

In this study, the following OMUVB products are used: OPEDRate (Overpass Erythemal Dose Rate), and OPIrd305, OPIrd310, OPIrd324 (Overpass Irradiance at $305 \mathrm{~nm}, 310 \mathrm{~nm}$ and $324 \mathrm{~nm}$, respectively). In addition, OMUVB dataset contains LambEquRef (Lambertian Equivalent Reflectivity at $360 \mathrm{~nm}$ ) which is used for cloud characterization. All these OMUVB products are obtained using the new version of the OMI level 1 (radiance and irradiance) and level 2 (atmospheric data products) data set named collection 3. This new version takes advantage of a coherent calibration and revised dark current correction (see NASA DISC site http://disc.gsfc.nasa.gov/Aura/OMI/ for OMI level 2 data. and Aura Validation data Center site at http://avdc.gsfc.nasa.gov for the OMI station overpass data). 


\subsection{Ground-based data}

The Brewer MK-III double monochromator spectrophotometer \#150 measures global UV spectral irradiance between 290 and $363 \mathrm{~nm}$ with spectral resolution (FWHM) $\sim 0.6 \mathrm{~nm}$, and wavelength accuracy of $0.05 \mathrm{~nm}$. A complete wavelength scan takes $4.5 \mathrm{~min}$. The spectrophotometer is periodically calibrated by comparison with a quartz-halogen NIST-traceable standard lamp (1000 W DXW type). This lamp presents an uncertainty of $1.56 \%$ at $250 \mathrm{~nm}$ and $1.12 \%$ at $350 \mathrm{~nm}$. This calibration transfer results in uncertainties of $\pm 5 \%$ in the Brewer spectral irradiance measurements (Vilaplana, 2004). In addition, the Brewer \#150 is inter-compared every two years against the transportable Quality Assurance of Spectral Ultraviolet Measurements in Europe (QASUME) reference spectrophotometer (Gröbner et al., 2005). All these calibration processes guarantee the $\sim 5 \%$ accuracy of the Brewer UV spectral measurements used in this study. Finally, a cosine correction has been applied to the measurements using a technique described in the work of Antón et al. (2008).

To analyze the aerosol effect on the bias of the OMUVB products, measurements from the automatic CIMEL sun- sky photometer were used. The instrument belongs to RIMAPHOTONS networks as part of the NASA AERONET network (http://aeronet.gsfc.nasa.gov). The CIMEL sun photometer measures direct sun and sky radiation at four wavelength channels, 440, 670, 870 and $1020 \mathrm{~nm}$ (10 nm FWHM for the visible channels) (Holben et al., 1998). The automatic cloud screening algorithm is applied to the raw data resulted in level 1.5 products (Smirnov et al., 2000). Aerosol optical depth (AOD) and the Ångström coefficient $(\alpha)$ from the AERONET direct sun data were analyzed to characterize the aerosol load and type similarly to Cachorro et al. (2006, 2008) and Toledano et al. (2007b).

The ground-based instruments are located at the "El Arenosillo" Atmospheric Sounding Station (ESAt-El Arenosillo). This station belongs to the Earth Observation, Remote Sensing and Atmosphere Department, National Institute of Aerospace Technology of Spain (INTA). It is located in the Gulf of Cadiz near the coast in Mazagón, Huelva, Spain $\left(37.1^{\circ} \mathrm{N}, 6.7^{\circ} \mathrm{W}, 20 \mathrm{~m}\right.$ a.s.1.). This site participates in the Global Ozone Observing System (GO3OS) of the Global Atmosphere Watch (GAW) program of World Meteorological Organization (WMO) as station \#213. Data gathering, retrieval and reporting procedures at these stations are standardized by the WMO quality assurance procedures.

\section{Methodology}

The UV irradiance weighted with the erythemal action spectrum adopted by the Commission Internationale de l'Eclairage (CIE) (McKinlay and Diffey, 1987) (denoted as UVER) and absolute spectral UV irradiances (Watts $/ \mathrm{nm} / \mathrm{m}^{2}$ ) (at $305 \mathrm{~nm}, 310 \mathrm{~nm}$ and $324 \mathrm{~nm}$ ) were used for the comparison between OMUVB products and Brewer measurements.

In order to obtain UVER data from the Brewer spectrophotometer, its measurements' range has to be expanded from $363 \mathrm{~nm}$ (actual limit of the measurements of this instrument) up to $400 \mathrm{~nm}$ (upper limit of the CIE standard spectrum). This correction is performed by the software developed by Martin Stanek at the Solar and Ozone Observatory of the Czech Hydrometeorological Institute (Stanek, 2007). An empirical correction of this error can be found in the work of Vilaplana et al. (2006).

For each day of Brewer observations the single OMI ground pixel most closely collocated with El Arenosillo station is selected as the best match. Thus, in this work, we used daily OMI pixels with centers from $0.1 \mathrm{~km}$ to $48 \mathrm{~km}$ from the site, being the average value $11.5 \mathrm{~km}$. In addition, in this comparison we used the Brewer UV-scan closest in time to the OMI overpass at $\sim 13: 45$. The average time difference between the Brewer measurements and the OMI overpass is only $6 \mathrm{~min}$. The OMI-Brewer data with time differences higher than $15 \mathrm{~min}$ ( $\sim 5 \%$ of all data) are removed in the comparison.

To select cloud-free conditions, the OMI Lambertian Equivalent Reflectivity (LER) at $360 \mathrm{~nm}$ was used. Thus, a day is considered cloud-free during OMI overpass when LER is lower than $10 \%$ (Kalliskota et al., 2000). The percentage of such cloud-free days is about $50 \%$ of the total amount of days at El Arenosillo station.

High aerosol events were identified according to the aerosol optical depth (AOD) measured with CIMEL sunphotometer. Unfortunately, this instrument was not equipped with UV filters during the period of study, being the channel that observes light with the shortest wavelength $(\mathrm{FWHM}=10 \mathrm{~nm}$ ). In order to examine the effects of aerosols on the differences between satellite and ground-based nearnoon CIE irradiances, $\mathrm{AOD}_{440}$ was daily averaged between 12:30 and 14:30 solar time on each day.

To investigate the effect of clouds and aerosols on the OMI bias, the following four datasets were analyzed:

Dataset 1: all sky conditions.

Dataset 2: all cloud-free cases (LER $<10 \%)$.

Dataset 3: cloud-free cases with low aerosol load $\left(\mathrm{LER}<10 \%\right.$ and $\left.\mathrm{AOD}_{440}<0.1\right)$.

Dataset 4: cloud-free cases with moderate-high aerosol load $\left(\mathrm{LER}<10 \%\right.$ and $\left.\mathrm{AOD}_{440}>0.25\right)$.

The selection of these data sets is based on a previous analysis of TOMS irradiance data (e.g., Antón et al., 2007). Regression analysis was performed separately for each subset and statistics such as the mean bias error (MBE) and the 
mean absolute bias error (MABE) were calculated. These statistics are obtained by the following expressions:

MBE $=100 \cdot \frac{1}{N} \sum_{i=1}^{N} \frac{\text { OMI }- \text { Brewer }}{\text { OMI }}$

$\mathrm{MABE}=100 \cdot \frac{1}{N} \sum_{i=1}^{N} \frac{\mid \mathrm{OMI}-\text { Brewer } \mid}{\mathrm{OMI}}$

In order to take into account the different number of data used in each dataset, the uncertainty of MBE and MABE is characterized by the standard error (SE), defined as:

$\mathrm{SE}=\frac{\mathrm{SD}}{\sqrt{N}}$

where SD is the standard deviation and $N$ is the number of data in each dataset.

\section{Results and discussion}

\subsection{All sky conditions}

Initially the OMUVB products were compared with simultaneous measurements performed by the Brewer spectrophotometer \#150 for all sky conditions. The number of days analyzed is 1272 during the period of study: October 2004December 2008 (80\% of the total days).

The results of the correlation between OMUVB and Brewer data are presented in Table 1. The regression analysis shows positive OMUVB bias characterized by regression slopes of 1.13 (UVER), 1.15 (UV $305 \mathrm{~nm}$ ), and 1.09 (UV $310 \mathrm{~nm}$ ), and 1.02 (UV $324 \mathrm{~nm}$ ), and with correlation coefficients higher than 0.90 . The RMSE statistics (residual error of the fit) is between $20 \%$ and $23 \%$, being larger for shorter wavelengths in agreement with the work of Kazadzis et al. (2009). As an example for this dataset, Fig. 1a shows the scatter plot for UVER data. The scatter plots for the spectral UV irradiances at the three wavelengths (not shown) present a very similar behavior.

Table 2 shows the parameters obtained from the relative OMI-Brewer differences. The positive sign of the MBE means that all OMUVB products overestimate on average the ground-based measurements. This average overestimation is $(12.27 \pm 0.50) \%$ for UVER data and varies from $(8.69 \pm 0.51) \%$ for $\mathrm{UV}$ at $324 \mathrm{~nm}$ to $(14.24 \pm 0.52) \%$ for $\mathrm{UV}$ at $305 \mathrm{~nm}$. In addition, the MABE parameter is between $13.6 \%$ for $\mathrm{UV}$ at $324 \mathrm{~nm}$ and $17.6 \%$ for UV at $305 \mathrm{~nm}$. The uncertainty of this last parameter is lower than $0.5 \%$, indicating the statistical significance of the values.

In this work, the OMI Lambertian Equivalent Reflectivity (LER) at $360 \mathrm{~nm}$ is used as proxy for analyzing the influence of cloudiness on the OMI-Brewer comparison. Using bins of size 5\%, Fig. 2 shows the MBE as a function of LER.
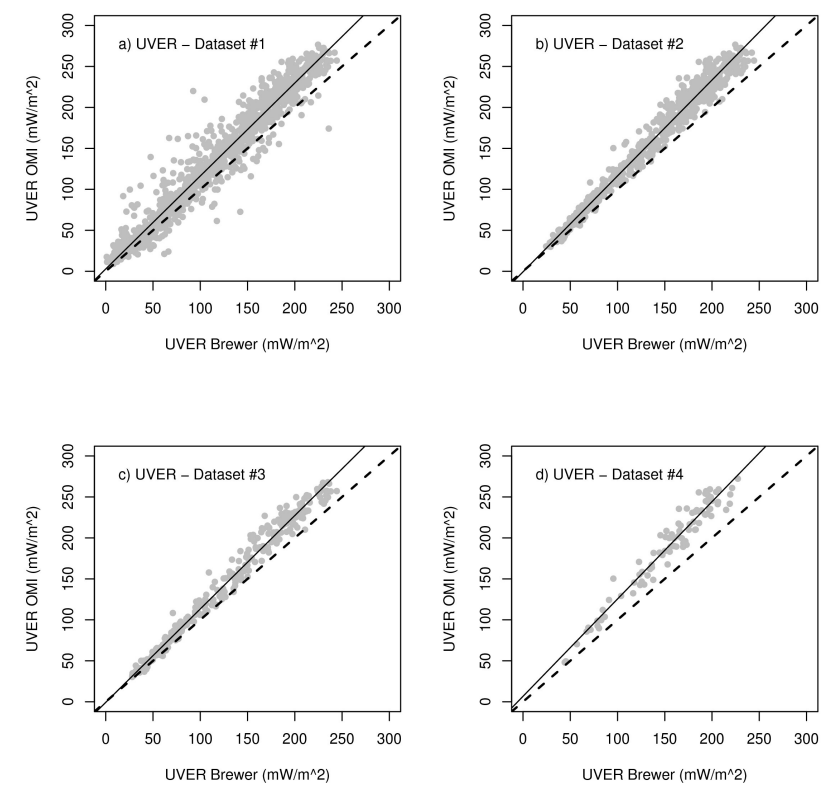

Fig. 1. (a) Correlation between OMI and Brewer UV products for all-sky conditions (dataset \#1) for the UV irradiance weighted by the CIE spectrum (UVER); (b) for cloud-free sky condition or dataset \#2; (c) dataset \#3 and (d) dataset \#4. The solid line is the least square linear regression line, and the dashed line symbolizes the ideal correlation of unit slope.

Error bars represent the standard errors (SE) of the bin that are plotted for UVER only for clarity.

The figure shows that the MBE parameter for UVER and the three spectral irradiances presents a stable behaviour on LER for low values of this proxy: MBE 5\%-15\% for $\mathrm{LER}<45 \%$. It can be seen a minimum value of MBE for LER $\sim 50 \%$ (biases have both positive and negative values). In addition, it is appreciable an increase of the relative differences for high LER values (thick clouds or high cloud optical depth) with a significant noise increase (larger error bars) in agreement with previous TOMS studies (i.e., Kalliskota et al., 2000; Chubarova et al., 2002; Cede et al., 2004; Antón et al., 2007). However we must emphasize that at our site the frequency of days with LER $>50 \%(8 \%)$ is much lower than cloud-free days ( $55 \%$ of days with LER $<10 \%$ ).

This result is related to the fact that the OMUVB products are an average over a satellite pixel ( 13 by $24 \mathrm{~km}$ for nadir viewing and $\sim 50 \mathrm{~km}$ off-nadir viewing directions). Thus, variability of cloudiness within the satellite pixel can lead to a significant difference between ground-based (a single point) and OMUVB data (pixel) (Weihs et al., 2008). Defining a criterion to select cloud-free conditions only using satellite information is a difficult issue. According to Kalliskota et al. (2000), days with LER $<10 \%$ could be considered cloud-free, being 719 cloud-free days at our site ( $\sim 55 \%$ of all days). This percentage confirms the prevalence of cloudless situations over the El Arenosillo station. 
Table 1. Results of linear regression analysis between OMI and Brewer UV products for all sky conditions (dataset \#1), cloud-free conditions (dataset \#2), cloud-free cases with low aerosol load (dataset \#3), and cloud-free cases with moderate-high aerosol load (dataset \#4). The parameters are the following: the slope of the regression, the standard error (SE) of the slope, the $\mathrm{Y}$ intercept, the SE of the Y intercept, the correlation coefficients $\left(R^{2}\right)$, and the root mean square errors (RMSE).

\begin{tabular}{|c|c|c|c|c|c|c|}
\hline \multicolumn{7}{|c|}{ DATASET \#1 } \\
\hline & Slope & $\begin{array}{r}\text { SE } \\
\text { (Slope) }\end{array}$ & $\begin{array}{l}\text { Y intercept } \\
\left(\mathrm{mW} / \mathrm{m}^{2}\right)\end{array}$ & $\begin{array}{r}\mathrm{SE}(\mathrm{Y} \text { intercept }) \\
\left(\mathrm{mW} / \mathrm{m}^{2}\right)\end{array}$ & $R^{2}$ & $\begin{array}{r}\text { RMSE } \\
(\%)\end{array}$ \\
\hline UVER & 1.13 & 0.01 & 2.51 & 0.96 & 0.94 & 20.7 \\
\hline UV 305 & 1.15 & 0.01 & 0.91 & 0.24 & 0.95 & 23.2 \\
\hline UV 310 & 1.09 & 0.01 & 2.11 & 0.51 & 0.94 & 21.1 \\
\hline UV 324 & 1.02 & 0.01 & 20.08 & 2.66 & 0.90 & 19.8 \\
\hline \multicolumn{7}{|c|}{ DATASET \#2 } \\
\hline UVER & 1.17 & 0.01 & -0.94 & 0.97 & 0.98 & 7.3 \\
\hline UV 305 & 1.17 & 0.01 & 0.27 & 0.25 & 0.98 & 8.9 \\
\hline UV 310 & 1.13 & 0.01 & 0.37 & 0.50 & 0.97 & 7.7 \\
\hline UV 324 & 1.09 & 0.01 & 7.13 & 2.51 & 0.96 & 6.6 \\
\hline \multicolumn{7}{|c|}{ DATASET \#3 } \\
\hline UVER & 1.14 & 0.01 & -0.79 & 1.14 & 0.98 & 7.0 \\
\hline UV 305 & 1.14 & 0.01 & 0.26 & 0.29 & 0.98 & 8.9 \\
\hline UV 310 & 1.11 & 0.01 & 0.10 & 0.58 & 0.98 & 7.3 \\
\hline UV 324 & 1.08 & 0.01 & 4.53 & 3.14 & 0.97 & 7.3 \\
\hline \multicolumn{7}{|c|}{ DATASET \#4 } \\
\hline UVER & 1.19 & 0.03 & 5.38 & 4.84 & 0.95 & 7.2 \\
\hline UV 305 & 1.21 & 0.03 & 1.33 & 1.18 & 0.96 & 8.0 \\
\hline UV 310 & 1.13 & 0.03 & 5.27 & 2.53 & 0.94 & 7.7 \\
\hline UV 324 & 1.02 & 0.04 & 46.42 & 12.44 & 0.89 & 7.0 \\
\hline
\end{tabular}

However, if Cimel AOD data are used to define cloud-free conditions at our station, then the cloud-free days represents a percentage of $68 \%$ of all days. Applying both OMI and AERONET cloud-screening reduces the percentage of cloud-free days to $\sim 49 \%$ of all days. Therefore, the selection of cloudy or cloud-free situations using only OMI LER data presents an inherent uncertainty, as it allows sub-pixel clouds.

Previous OMUVB validation studies (e.g., Taskanen et al., 2007; Buchard et al., 2008; Ialongo et al., 2008) were performed at solar noon. Since the difference in atmospheric conditions (clouds, aerosols) between local noon and OMI overpass time ( $\sim 01: 45$ p.m.) can affect such comparisons (Ialongo et al., 2008) here the OMI-Brewer comparisons were performed at the OMI overpass time.

\subsection{Data set 2: cloud-free conditions}

For this data set the OMI versus Brewer correlation results for all OMUVB products are shown in Table 1. Figure 1b shows the correlation plot for UVER data (similar plots for the spectral UV wavelengths not shown). Compared with

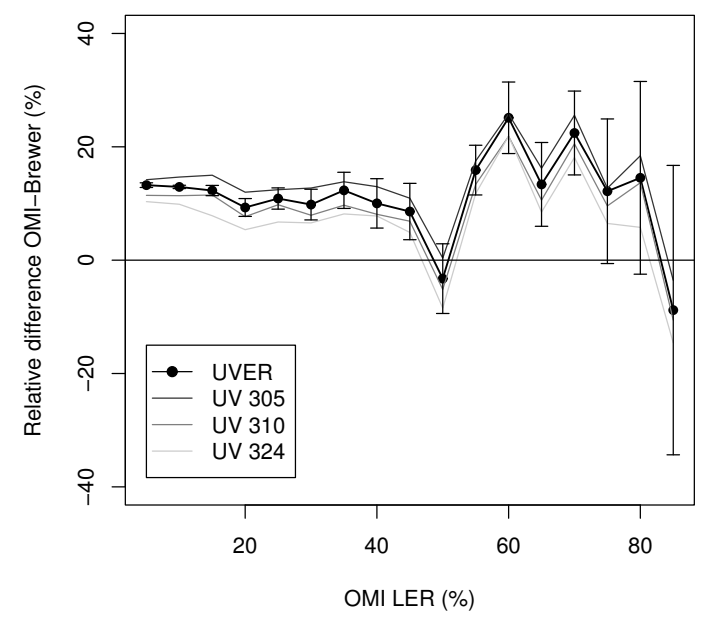

Fig. 2. Dependence of the relative difference between OMI and Brewer UV products with respect to the OMI Lambertian Equivalent Reflectivity (LER) at $360 \mathrm{~nm}$ for all sky conditions (dataset \#1) taking binned data. The size of the bins is $5 \%$. 
all sky conditions (Fig. 1a) the noise is considerably smaller and correlation is tighter. The statistical parameters show that agreement is excellent for all OMUVB products. The noise is also significantly lower for cloud-free days (RMSE lower than 10\%) than for all sky conditions (RMSE higher than $20 \%$ ), which is consistent with the assumption that clouds are the main source for the scatter between satellite and groundbased UV data. Table 2 presents the statistical parameters of the relative differences between satellite and ground-based data, showing that the biases remain and even become more significant for this cloud-free dataset \#2. This finding is related to the absence of the cloudiness compensating effect occurred for dataset \#1 (see Fig. 2).

Total ozone column (TOC) data retrieved from OMITOMS algorithm (Bhartia and Wellemeyer, 2002) were also compared with Brewer TOC measurements at El Arenosillo for this dataset (not shown). Although the correlation between satellite and ground-based TOC data is excellent $\left(R^{2} \sim 0.99\right)$, OMI total ozone data are on average $1.31 \%$ smaller than Brewer measurements. This result agrees with the work of Antón et al. (2009) which validated OMI ozone products with ground-based observations from network of Spanish Brewer spectrophotometers for the period 20052007. A notable underestimation of TOC values from OMI algorithm could potentially explain the overestimation found for the OMUVB products (especially for the shortest wavelengths), since the OMUVB algorithm uses the TOC values from OMI-TOMS as input. Nevertheless, it is clear that the small TOC underestimation found in this work (1.31\%) cannot explain $13 \%$ bias in UV data.

Using AOD data from collocated CIMEL sun-photometer, we analyzed the OMI-Brewer bias (MBE) as a function of the AOD for cloud-free days similarly to the previous analysis using TOMS UV data (e.g., Antón et al., 2008). Figure 3 (top) shows a weak relationship between the relative differences in UV and AOD, with a correlation coefficient $\sim 0.4$.

Arola et al. (2005) previously studied TOMS surface UV bias at $324 \mathrm{~nm}$ as function of aerosol column absorption optical depth (AAOD). They reported a significant correlation (about 0.8) higher than the one found in this study. Kazantzidis et al. (2006) made the same studies but with $\mathrm{AOD}$ and they found a correlation greater than 0.65 . Buchard et al. (2008) also analyzed relationship between the AOD and the OMI-surface UV bias, founding correlation coefficient is about 0.6, while Ialongo et al. (2008) found similar correlation $\left(R^{2} \sim 0.5\right)$ at SZA larger than 55 degrees.

Figure 3 (bottom) shows MBE as function of AOD, binning the data with a 0.1 AOD bins. Larger relative UV differences correspond to larger AOD. As seen from the figure the OMI UV bias increases with increase in AOD, in agreement with earlier findings. Therefore, under cloud-free conditions aerosol is the major parameter affecting the bias in satellite derived UV irradiance. This can be explained by the fact that OMUVB algorithm does not properly account for the absorbing aerosols in the boundary layer (Krotkov et al.,
Table 2. Statistical parameters of relative differences between OMI and Brewer UV products irradiances for all sky conditions (dataset $\# 1$ ), cloud-free conditions (dataset \#2), cloud-free cases with low aerosol load (dataset \#3), and cloud-free cases with moderate-high aerosol load (dataset \#4). The parameters are the following: the number of data $(N)$, the mean bias error (MBE), the standard error (SE) of the MBE, the mean absolute bias error (MABE), and the SE of the MABE.

\begin{tabular}{|c|c|c|c|c|c|}
\hline \multicolumn{6}{|c|}{ DATASET \#1 } \\
\hline & $N$ & $\begin{array}{r}\mathrm{MBE} \\
(\%)\end{array}$ & $\begin{array}{r}\mathrm{SE}(\mathrm{MBE}) \\
(\%)\end{array}$ & $\begin{array}{r}\text { MABE } \\
(\%)\end{array}$ & $\begin{array}{r}\mathrm{SE}(\mathrm{MABE}) \\
(\%)\end{array}$ \\
\hline UVER & 1272 & +12.27 & 0.50 & 15.96 & 0.41 \\
\hline UV 305 & 1272 & +14.24 & 0.52 & 17.61 & 0.42 \\
\hline UV 310 & 1272 & +10.64 & 0.51 & 14.94 & 0.42 \\
\hline UV 324 & 1272 & +8.69 & 0.51 & 13.62 & 0.41 \\
\hline \multicolumn{6}{|c|}{ DATASET \#2 } \\
\hline UVER & 703 & +13.01 & 0.24 & 13.13 & 0.23 \\
\hline UV 305 & 703 & +14.46 & 0.26 & 14.66 & 0.25 \\
\hline UV 310 & 703 & +11.37 & 0.25 & 11.59 & 0.23 \\
\hline UV 324 & 703 & +10.02 & 0.22 & 10.26 & 0.20 \\
\hline \multicolumn{6}{|c|}{ DATASET \#3 } \\
\hline UVER & 304 & +10.87 & 0.36 & 11.13 & 0.33 \\
\hline UV 305 & 304 & +12.18 & 0.41 & 12.59 & 0.37 \\
\hline UV 310 & 304 & +9.22 & 0.37 & 9.66 & 0.33 \\
\hline UV 324 & 304 & +8.43 & 0.33 & 8.83 & 0.30 \\
\hline \multicolumn{6}{|c|}{ DATASET \#4 } \\
\hline UVER & 94 & +18.22 & 0.58 & 18.22 & 0.58 \\
\hline UV 305 & 94 & +19.28 & 0.61 & 19.28 & 0.61 \\
\hline UV 310 & 94 & +16.54 & 0.61 & 16.54 & 0.61 \\
\hline UV 324 & 94 & +14.52 & 0.60 & 14.52 & 0.60 \\
\hline
\end{tabular}

2005; Taskanen et al., 2007; Arola et al., 2009). Spectrally the largest UV differences occur at the shortest wavelengths (Fig. 3, bottom) where the uncertainly in both satellite algorithm and Brewer instrument are higher (Kazantzidis et al., 2006).

\subsection{Data set 3: cloud-free conditions with low aerosol load}

The number of pair of cases OMI-Brewer selected for this dataset is 304 , representing the $23 \%$ of all days within the analyzed period. The atmospheric conditions corresponding to this dataset are more similar to the model assumptions used in the OMUVB algorithm and, therefore, a better agreement with ground-based measurements is expected.

Figure 1c shows the scatter plot between OMI and Brewer for UVER data. Similar plots were elaborated for spectral UV irradiances at 305, 310 and $324 \mathrm{~nm}$ (not shown). All scatter plots show positive OMI bias and an excellent correlation for the four cases $\left(R^{2} \sim 0.98\right)$ as illustrated in Table 1 
which also shows statistical errors of the slope and the intercept. These results indicate that the overestimation found in the OMUVB products is clearly reduced for cloud-free and aerosol-free sky conditions. These results agree with early TOMS UV validation studies (Krotkov et al., 1998; Cede et al., 2004; Antón et al., 2007).

Table 1 shows that the RMSE values for this dataset are lower than results obtained for all sky conditions. Thus, for UVER comparison, the RMSE decreases from $20.7 \%$ (all sky conditions) down to $7.0 \%$ (cloud-free cases with low aerosol load). To summarize, the cloudiness and aerosols explain a percentage of RMSE variation of $65 \%$ for UVER, $62 \%$ for UV irradiance at $305 \mathrm{~nm}, 65 \%$ for UV irradiance at $310 \mathrm{~nm}$ and $69 \%$ for the UV irradiance at $324 \mathrm{~nm}$.

Table 2 shows statistical parameters of the relative differences between Brewer and OMUVB products. It can be seen the significant decrease in the MBE and MABE parameters when cases with low aerosol load are selected. It is remarkable that the MBE and MABE values are similar for spectral UV irradiance at $310 \mathrm{~nm}$ and $324 \mathrm{~nm}$, suggesting that the OMI-Brewer differences are not related to ozone absorption, in agreement to the explanation given in Sect. 4.2.

It should be noted that not all of this bias is due to the OMUVB algorithm, but also due to the Brewer measurement uncertainties related to the cosine response, absolute calibration, etc. Furthermore, note that also a $2-3 \%$ of bias is also due to the differences between the modelled OMUVB algorithm data and Brewer measurements under cloud-free conditions.

\subsection{Data set 4: cloud-free conditions with moderate-high aerosol load}

The number of days selected for this dataset is 90, representing $7 \%$ of the whole cloud-free dataset. The cases with moderate-high aerosol optical depth have been analyzed according to the aerosol climatology in our area (Toledano, 2005; Cachorro et al., 2006; Toledano et al., 2007b).

Figure 1d shows the scatter plot of OMI versus Brewer UVER data. The UVER and spectral UV data (not shown) present a notable OMI overestimation, but the correlation remains significant ( $R^{2}$ between 0.89 and 0.96 , and RMSE values between $7.0 \%$ and $8.0 \%$ ). Other informative parameters of the regression are shown in Tables 1 and 2.

It can be seen from the Table 2 for this dataset the MBE and MABE parameters more strongly depend on UV wavelength (as wavelength decreases, MABE increases). This wavelength dependence of OMI-Brewer bias for moderatehigh aerosol load may be partially attributed to the aerosol influence over the OMUVB products. Aerosols can also increase effective absorption path for tropospheric ozone and other anthropogenic gases causing more effective UV reduction at shorter UV wavelengths (Bernard et al., 2003; Kaskaoutis et al., 2006; Badarinath et al., 2007).
If the statistical parameters obtained for the dataset \#3 and \#4 are compared (Tables 1 and 2), it can be seen that the RMSE, MBE and MABE parameters are significantly higher for the dataset \#4 than for the dataset \#3. Thus, for UVER comparison, the MBE is $(+10.87 \pm 0.36) \%$ for low aerosol loading cases, and $(+18.22 \pm 0.58) \%$ for high aerosol load. This overestimation is mainly due to the fact that current OMUVB algorithm assumes no absorbing aerosols in the boundary layer. This assumption produces two effects over OMUVB algorithm during high aerosol load conditions. Firstly, the obvious UV radiation overestimation due to the neglected aerosol absorption, and secondly, an underestimation of the effective cloud optical depth (COD). This parameter is obtained by OMI measurements of the top-ofthe-atmosphere radiance at $360 \mathrm{~nm}$, which is reduced by the presence of absorbing aerosol in the troposphere. Since the obtained COD is used to determine the spectral transmission of UV irradiance relative to the clear sky conditions, the COD underestimation by OMI for high aerosol load conditions produces an additional overestimation in UV radiation products (Krotkov et al., 1998, 2001, 2002).

Our results are in concordance with the study of Weihs et al. (2008) who reported an increase in the ratio of OMI UVER data to the ground measured UVER as a function of $\mathrm{AOD}$ at $368 \mathrm{~nm}$. This ratio increased from $1.05(\mathrm{AOD}=0.15)$ to 1.35 (AOD=0.6). Several studies (e.g., Krotkov et al., 2004, 2005; Arola et al., 2005; Kazadzis et al., 2009) have suggested off-line corrections for absorbing aerosols if the AAOT (absorbing aerosol optical thickness) is known or can be estimated at the site. In this sense, Arola et al. (2009) have recently proposed a correction for absorbing aerosols by using global monthly aerosol climatology and applying the parameterization suggested by Krotkov et al. (2005). The problem is that currently, there are no standard methods for measuring AAOT (or aerosol single-scattering albedo, SSA) in the UV wavelengths even from the ground. Such measurements are currently available only at few sites (Krotkov et al., 2005; Arola et al., 2007). AAOT or SSA values can be obtained in AERONET aerosol stations but they are determined only in visible-infrared wavelengths (shortest $440 \mathrm{~nm}$ ) and with a high associated uncertainty. Otherwise, new satellite aerosol absorption product from the OMI (Torres et al., 2007), if proved sensitive to boundary-layer aerosol, could be used for operational improvement in the future version of the OMUVB algorithm. This is currently the subject of ongoing research.

Therefore taking into account currently available aerosol information at our site we need a) to evaluate the absorbing aerosols optical thickness at our site and b) to analyze its influence in OMI bias. This is an extensive work which has been carried out in a companion paper (Cachorro et al., 2010). 

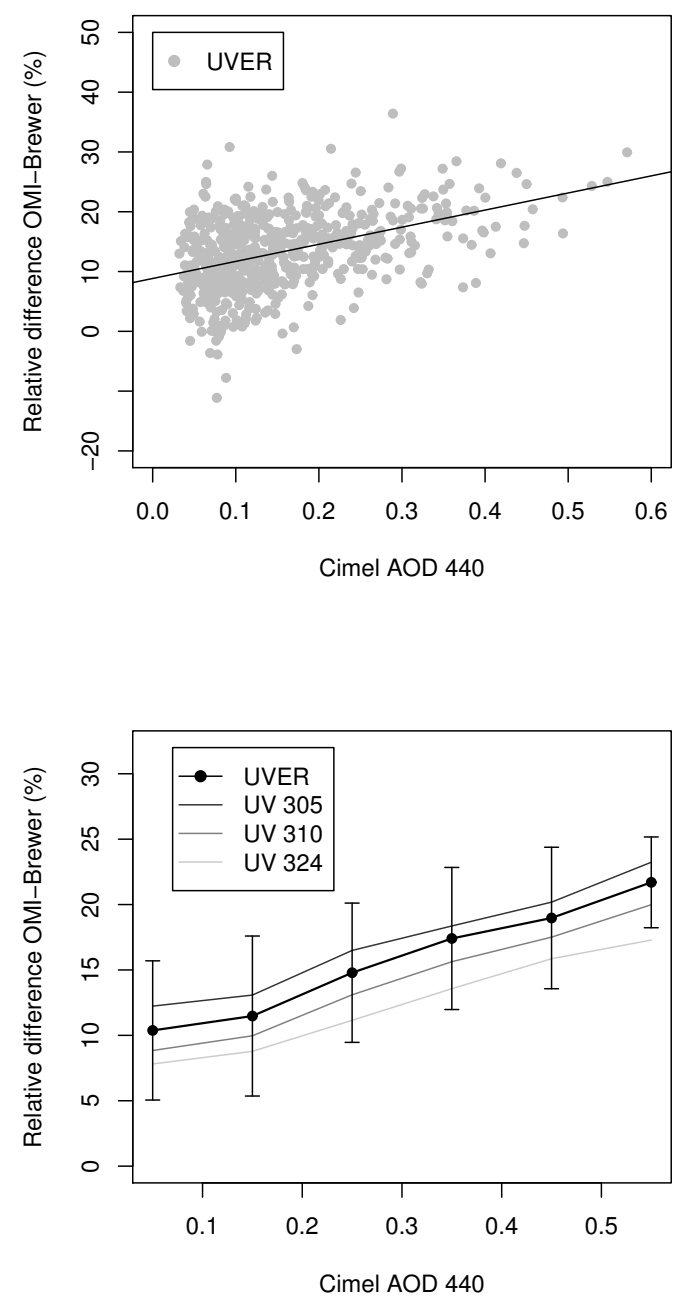

Fig. 3. Top) Dependence of the relative difference between OMI and Brewer UVER data with respect to the aerosol optical depth (AOD) at $440 \mathrm{~nm}$ measured from the Cimel photometer at El Arenosillo station for cloud-free conditions (dataset \#2). Bottom) the same as before but taking binned data for the four UV OMI products. The data are binned with a 0.1 AOD bins.

\subsection{Seasonal dependence}

Buchard et al. (2008) analyzed the dependence of the relative differences between OMI UV data and ground-based measurements on SZA, showing larger discrepancies for SZA higher than $65^{\circ}$. Kazadzis et al. (2009) showed no statistically significant dependence on SZA for the OMI-Brewer relative UV differences at Thessaloniki. Thus, this dependence is also analyzed in this study. In Fig. 4 the relative differences (MBE) between ground-based and OMI UVER data are compared as a function of the OMI ground pixel SZA for all sky conditions. Figure 5 shows similar binned data including all OMI data sets with error bars representing standard errors. The data are binned with a $4.25^{\circ}$ SZA bins.

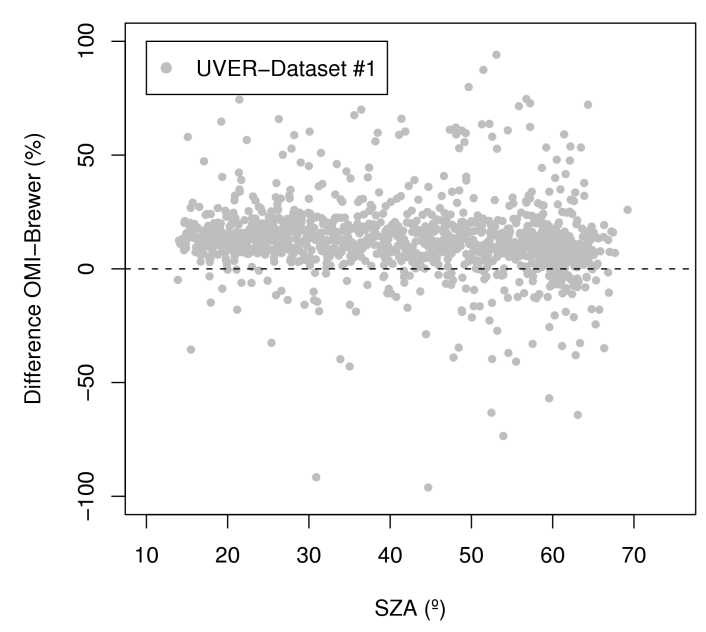

Fig. 4. Dependence of the relative difference between OMI and Brewer for UVER with respect to OMI solar zenith angle (SZA).
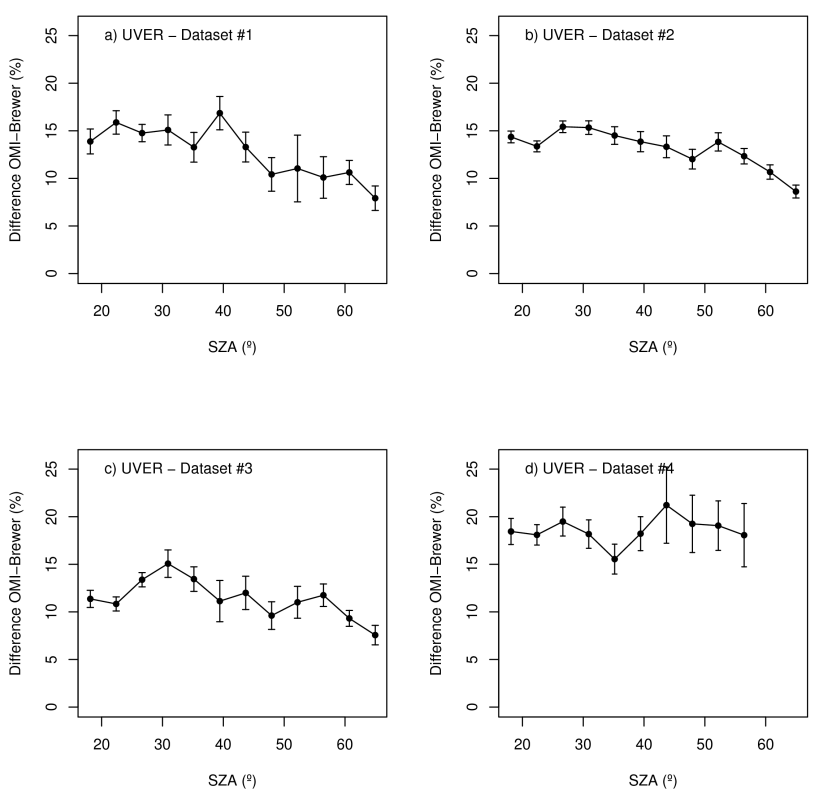

Fig. 5. The same as Fig. 4 but taking binned data for (a) all sky conditions (dataset \#1); (b) for cloud-free sky condition or dataset \#2; (c) dataset \#3 and (d) dataset \#4. The data are binned with $4.25^{\circ}$ bins.

For dataset \#1 (all sky data), Figs. 4 and 5a show a small bias dependence (about $8 \%$ ) on SZA, with the bias decreasing with SZA, from about $17 \%$ to $9 \%$. For dataset \#2 and \#3 (Fig. 5b and 5c), this dependence is reduced and no dependence is seen for dataset \#4 (Fig. 5d). Although only UVER is shown, this evaluation was also performed for the other spectral UV products and we observe that $324 \mathrm{~nm}$ wavelength compares best. 

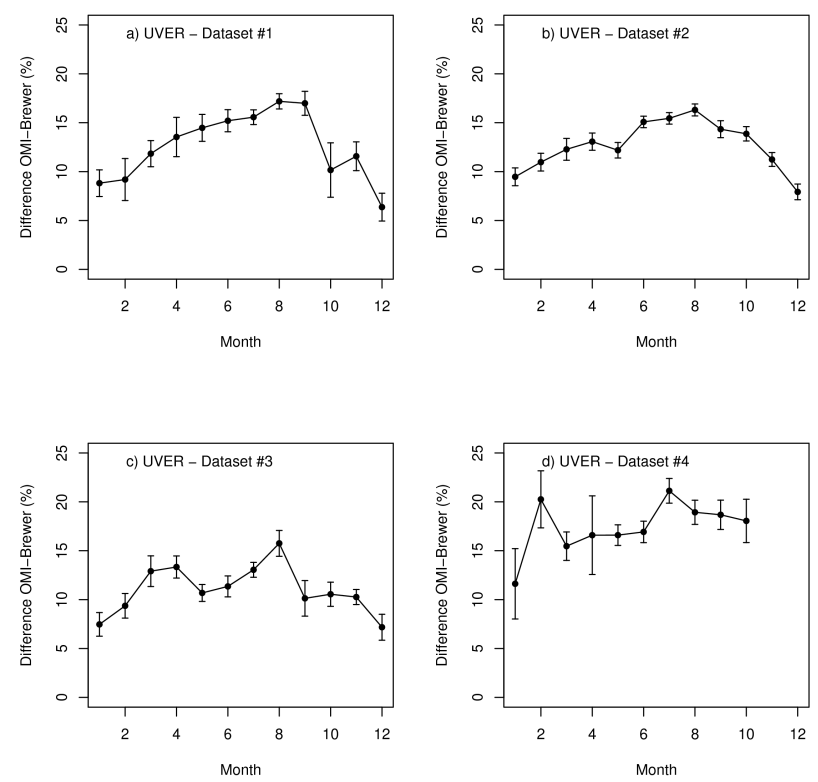

Fig. 6. Monthly evolution of the relative difference between OMI and Brewer UVER data for (a) all sky conditions (dataset \#1); (b) for cloud-free sky condition or dataset \#2 (up right); (c) dataset \#3 and (d) dataset \#4.

The UV bias time series as function of month (Fig. 6) reveal a notable seasonal dependence for the dataset \#1, with amplitude about $10 \%$, increasing from $10 \%$ in winter to almost $20 \%$ in summer. This seasonal amplitude is reduced by a factor of 2 when cloud-free and low aerosol load cases are selected (dataset \#3), showing two peaks as observed in a previous TOMS-Brewer comparison (Antón et al., 2007). These two peaks in March-April and summer are consistent with AOD climatology at our station and roughly correspond to the periods with frequent desert dust intrusions (Toledano et al., 2007a, b). This indicates that clouds and aerosols together with SZA greatly affect the seasonal dependence found in this work for all sky conditions.

\section{Conclusions}

This study focuses on the comparison between OMI and Brewer surface UV products at El Arenosillo station (South of Spain) for the period October 2004-December 2008 where we studied the influence of several factors: clouds, aerosols, ozone, solar elevation and aerosols. Our results confirm that OMUVB products overestimate the Brewer measurements with bias between $8 \%$ and $14 \%$ for all sky conditions. We found no significant changes when cloud-free conditions are selected.

The relationship between the OMI-Brewer differences and the OMI LER showed a slight dependence with OMI LER, with notable bias for larger values. Thus, the cloudiness is the main factor that introduces scatter in the satellite-groundbased correlation for all sky conditions. This study shows that the OMI-TOMS total ozone column used as input in the OMUVB algorithm has no affect on the relative differences between OMI and Brewer UV products.

The relative differences between OMI and Brewer UV products show a modest decrease with SZA for all sky conditions except days with high aerosol loading, when the bias is near constant. This fact causes a pronounced seasonal dependence of the bias with the largest differences occurring during summer. The amplitude of this seasonal dependence is notably reduced when cloud-free and low aerosol loads conditions are selected, but each data set shows its own features. Thus, for instance, cloud-free conditions (dataset \#2) and low aerosol load (dataset \#3) clearly shows the modulation given by the aerosol climatology in this area.

The influence of aerosols is broadly observed when cloudfree case is considered in our station. According to the recent OMI UV validation results of Taskanen et al. (2008), our comparisons fall within "the middle of the range" of other ground UV stations. However, new measurements of aerosol absorption (i.e. single scattering albedo, SSA) must be conducted to improve the estimated OMI UV values. A more detailed analysis of aerosol optical properties at our site has been carried out in a companion paper (Cachorro et al., 2010).

Acknowledgements. The authors thank the OMI International Science Team for the satellite data used in this study and also to the teams of aerosol networks GSFC-NASA and PHOTONS. This work has been partially supported by MICIN under coordinated project CGL2008-05939-C03/CLI of UVA-INTA-UEX. Also this work is financed by GR220 project of "Junta de Castilla y León". Manuel Antón thanks Ministerio de Ciencia e Innovación and Fondo Social Europeo for the award of a postdoctoral grant (Juan de la Cierva).

Edited by: W. Lahoz

\section{References}

Antón, M., Cachorro, V. E., Vilaplana, J. M.,. Krotkov, N. A, Serrano, A., Toledano, C., de la Morena, B., and Herman, J. R.: Total ozone mapping spectrometer retrievals of noon erythemalCIE ultraviolet irradiance compared with Brewer ground-based measurements at El Arenosillo (southwestern Spain), J. Geophys. Res., 112, D11206, doi:10.1029/2006JD007254, 2007.

Antón, M., Serrano, A., Cancillo, M. L., Vilaplana, J. M., Cachorro, V. E., and Gröbner, J.: Correction of angular response error in Brewer UV irradiance measurements, J. Atmos. Ocean. Tech., 25, 2018-2017, doi:10.1175/2008JTECHA1040.1, 2008.

Antón, M., López, M., Vilaplana, J. M., Kroon, M., McPeters, R., Bañón, M., and Serrano, A. : Validation of OMI-TOMS and OMI-DOAS total ozone column using five Brewer spectroradiometers at the Iberian Peninsula, J. Geophys. Res., 114, D14307, doi:10.1029/2009JD012003, 2009. 
Arola, A., Kazadzis, S., Krotkov, N., Bais, A., Gröbner, J., and Herman, J. R.: Assessment of TOMS UV bias due to absorbing aerosols, J. Geophys. Res., 110, D23211, doi:10.1029/2005JD005913, 2005.

Arola, A., Lindfors, A., Natunen, A., and Lehtinen, K. E. J.: A case study on biomass burning aerosols: effects on aerosol optical properties and surface radiation levels, Atmos. Chem. Phys., 7, 4257-4266, doi:10.5194/acp-7-4257-2007, 2007.

Arola, A., Kazadzis, S., Lindfors, A., et al.: A new approach to correct for absorbing aerosols in OMI UV, Geophys. Res. Lett., 36, L22805, doi:10.1029/2009GL041137, 2009.

Badarinath, K. V. S., Kharol, S. K., Kaskaoutis, D. G., and Kambezidis, H. D.: Influence of atmospheric aerosols on solar spectral irradiance in an urban area, J. Atmos. Sol.-Terr. Phys., 69, 589-599, 2007.

Bhartia, P. K. and Wellemeyer, C. W.: TOMS-V8 total O3 algorithm, in: OMI Algorithm Theoretical Basis Document, vol. II, edited by: Bhartia, P. K., NASA Goddard Space Flight Cent., Greenbelt, Md., 15-32, available online at: http://www.knmi.nl/ omi/documents/data/OMI_ATBD_Volume_2_V2.pdf, 2002.

Bernard, W. F., Saxena V. K., Wenny B. N., and DeLuisi J. J.: Daily surface UV exposure and its relationship to surface pollutant measurements, J. Air Waste Manage. Assoc., 53, 237-245, 2003.

Buchard, V., Brogniez, C., Auriol, F., Bonnel, B., Lenoble, J., Tanskanen, A., Bojkov, B., and Veefkind, P.: Comparison of OMI ozone and UV irradiance data with ground-based measurements at two French sites, Atmos. Chem. Phys., 8, 4517-4528, doi:10.5194/acp-8-4517-2008, 2008.

Cachorro, V. E., Vergaz, R., de Frutos, A. M., Vilaplana, J. M., Henriques, D., Laulainen, N., and Toledano, C.: Study of desert dust events over the southwestern Iberian Peninsula in year 2000: two case studies, Ann. Geophys., 24, 1493-1510, doi:10.5194/angeo-24-1493-2006, 2006.

Cachorro, V. E., Toledano, C. , Prats, N., Sorribas, M., Mogo, S., Berjón, A., Torres, B.,. Rodrigo, R , de Frutos, A. M., and de la Rosa, J.: The strongest desert dust intrusion mixed with smoke over the Iberian Peninsula registered with sun-photometry, J. Geophys. Res., 113, D14504, doi:10.1029/2007JD009582, 2008.

Cachorro, V. E., Toledano, C., Antón, M., Berjón, A., de Frutos, A., Vilaplana, J. M., Arola, A., and Krotkov, N. A.: Comparison of UV irradiances from Aura/Ozone Monitoring Instrument (OMI) with Brewer measurements at El Arenosillo (Spain) - Part 2: Analysis of site aerosol influence, Atmos. Chem. Phys. Discuss., 10, 16385-16423, doi:10.5194/acpd-10-16385-2010, 2010.

Cede, A., Luccini, E. , Nuñez, L., Piancetini, R. D., Blumthaler, M., and Herman, J. R.: TOMS-derived erythemal irradiance versus measurements at stations of Argentine UV Monitoring Network, J. Geophys. Res., 109, D08109, doi:10.1029/2004JD004519, 2004.

Chubarova, N. Y.,. Yurova, A. Y, Krotkov, N.,. Herman, J. R, and Barthia, P. K: Comparison between ground measurements of broadband ultraviolet irradiance (300 to $380 \mathrm{~nm}$ ) and total ozone mapping spectrometer ultraviolet estimates at Moscow from 1979 to 2000, Opt. Eng., 41, 3070-3081, 2002.

Fioletov, V. E., Kimlin, M. G., Krotkov, N., McArthur, L. J. B., Kerr, J. B., Wardle, D. I., Herman, J. R., Meltzer, R., Mathews, T. W., and Kaurola, J.: UV index climatology over the United States and Canada from groundbased and satellite estimates, J. Geo- phys. Res., 109, D22308, doi:10.1029/ 2004JD004820, 2004.

Gröbner, J., Schreder, J., Kazadzis, S., Bais, A. F., Blumthaler, M., Görts, P., Tax, R., Koskela, T., Seckmeyer, G., Webb, A. R., and Rembges, D.: Traveling reference spectroradiometer for routine quality assurance of spectral solar ultraviolet irradiance measurements, Appl. Opt., 44, 5321-5331, 2005.

Holben, B. N., Eck, T. F., Slutsker, I., Tanré, D., Buis, J. P., Setzer., A., Vermote, E. F. Reagan, J. A., Kaufman, I. Y., Nakajima, T., Lavenu, F., Jankowiak, I., and Smirnov, A.: ERONET - A federated instrument network and data archive for aerosol characterization, Remote Sens. Environ., 66, 1-16, 1998.

Ialongo, I., Casale, G. R., and Siani, A. M.: Comparison of total ozone and erythemal UV data from OMI with ground-based measurements at Rome station, Atmos. Chem. Phys., 8, 32833289, doi:10.5194/acp-8-3283-2008, 2008.

Kalliskota, S., Kaurola, J., Taalas P., Herman, J., Celarier, E., and Krotkov, N. : Comparison of daily UV doses estimated from Nimbus 7/TOMS measurements and ground-based spectroradiometer data, J. Geophys. Res., 105, 4273-4277, 2000.

Kaskaoutis, D. G., Kambezidis, H. D., Jacovides, C. P., and Steven, M. D: Modification of solar radiation components under different atmospheric conditions in the Greater Athens Area, Greece, J. Atmos. Sol.-Terr. Phys., 68, 1043-1052, 2006.

Kazantzidis, A., Bais, A. F., Grobner, J., Herman, J. R., Kazadzis, S., Krotkov, N., Kyrö, E., den Outer, P. N., Garane, K., Görts, P., Lakkala, K., Meleti, C., Slaper, H., Tax, R. B., and Turunen T.: Comparison of satellite-derived UV irradiances with groundbased measurements at four European stations, J. Geophys. Res., 111, D13207, doi:10.1029/2005JD006672, 2006.

Kazadzis, S., Bais, A., Arola, A., Krotkov, N., Kouremeti, N., and Meleti, C.: Ozone Monitoring Instrument spectral UV irradiance products: comparison with ground based measurements at an urban environment, Atmos. Chem. Phys., 9, 585-594, doi:10.5194/acp-9-585-2009, 2009.

Krotkov, N. A., Barthia, P. K., Herman, J. R., Fioletov, V., and Kerr, J.: Satellite estimation of spectral surface UV irradiance in the presence of tropospheric aerosols, J. Geophys. Res., 103, 87798793, 1998.

Krotkov, N. A., Herman, J. R., Barthia, P. K., Fioletov, V., and Ahmad, Z.: Satellite estimation of spectral surface UV irradiance 2. Effects of homogeneous clouds and snow, J. Geophys. Res., 106, 11743-11759, 2001.

Krotkov, N. A., Herman, J. R., Barthia, P. K., Seftor, C., Arola, A., Kaurola, J., Kalliskota, S., Taalas, P., and Geogdzhaev, I. V.: Version 2 total ozone mapping spectrometer ultraviolet algorithm: Problems and enhancements, Opt. Eng., 41(12), 30283039, 2002.

Krotkov, N., Herman, J., Fioletov, V., Seftor, C., Larko, D., Vasilkov, A., and Labow, G.: Boundary layer absorbing aerosol correction of an expanded UV irradiance database from satellite Total Ozone Mapping Spectrometer, in Proceedings of the XX Quadrennial Ozone Symposium, June 2004, Kos, Greece, 11591160, 2004.

Krotkov, N. A., Barthia, P. K., Herman, J. R., Slusser, J., Scott, G., Labow, G., Vasilkov, A. P., Eck, T. F., Dubovik, O., and Holben, B. N.: Aerosol ultraviolet absorption experiment (2000 to 2004), part 2: Absorption optical thickness, refractive index, and single scattering albedo, Opt. Eng., 44(4), 041005, doi:10.1117/1.1886819, 2005. 
Levelt, P. F., Hilsenrath, E., Leppelmeier, G. W., Van den Oord, G. H. J., Bhartia, P. K., Tamminen, J., De Haan, J. F., and Veefkind, J. P. : The Ozone Monitoring Instrument, IEEE T. Geosci. Remote, 44(5), 1093-1101, 2006.

McKenzie, R. L., Seckmeyer, G., Bais, A. F., Kerr, J. B., and Madronich, S.: Satellite retrievals of erythemal UV dose compared with groundbased measurements at northern and southern midlatitudes, J. Geophys. Res., 106, 24051-24062, 2001.

McKinlay, A. F. and Diffey, B. L.: A reference spectrum for ultraviolet induced erythema in human skin, CIE-J., 6, 21-27, 1987.

Meloni, D., di Sarra A., Herman, J. R., Monteleone, F., and Piacentino, S.: Comparison of ground-based and total ozone mapping spectrometer erythemal UV doses at the Island of Lampedusa in the period 1998-2003: Role of tropospheric aerosols, J. Geophys. Res., 110, D01202, doi:10.1029/2004JD005283, 2005.

Sabburg, J., Rives, J. E., Meltzer, R. S., Taylor, T., Schmalzle, G., Zheng, S., Huang, N., Wilson, A., and Udelhofen, P. M.: Comparison of corrected daily integrated erythemal data from the U.S. E.PA/UGA network of Brewer spectroradiometer with model and TOMS-inferred data, J. Geophys. Res., 107(D23), 4676, doi:10.1029/2001JD001565, 2002.

Schoeberl, M. R., Douglass, A. R., Hilsenrath, E., Bhartia, P. K., Beer, R., Waters, J. W., Gunson, M. R., Froidevaux, L., Gille, J. C., Barnett, J. J., Levelt, P. E., and DeCola, P.: Overview of the EOS Aura Mission, IEEE T. Geosci. Remote, 4, 1066-1074, 2006.

Smirnov, A., Holben, B. N., Eck, T. F., Dubovik, O., and Slutsker, I.: Cloud screening and quality control algorithms for the AERONET database, Remote Sens. Environ., 73, 337-349, 2000.

Stanek, M.: Total Ozone and UV Radiation Monitoring Software, available online at: http://www.o3soft.eu/, 2007.

Tanskanen, A., Krotkov, N. A. Herman, J. R., and Arola, A.: Surface Ultraviolet Irradiance From OMI, IEEE T. Geosci. Remote, 44, 1267-1271, doi:10.1109/TGRS.2005.862203, 2006.

Tanskanen, A., Lindfors, A., Maatta, A., Krotkov, N., Herman, J., Kaurola, J., Koskela, T., Lakkala, K., Fioletov, V., Bernhard, J., McHenzie, R., Kondo, Y., O’Neill, M., Slaper, H., den Outer, P., Bais, A. F., and Tamminen, J.: Validation of daily erythemal doses from OMI with ground-based UV measurement data, J. Geophys. Res., 112, D24S44, doi:10.1029/2007JD008830, 2007.
Toledano, C.: Climatología de los aerosoles mediante la caracterización de propiedades ópticas y masas de aire en la estación 'El Arenosillo' de la red AERONET, PhD Dissertation, Universidad de Valladolid (Spain), 2005.

Toledano, C., Cachorro, V. E., de Frutos, A. M., Sorribas, M., Prats, N., and de la Morena, B.: Inventory of African desert dust events over the southwestern Iberian Peninsula in 2000 2005 with an AERONET Cimel Sun photometer, J. Geophys. Res., 112, D21201, doi:10.1029/2006JD008307, 2007a.

Toledano, C., Cachorro, V. E., Sorribas, M., Berjón, A., de la Morena, B. A., de Frutos, A. M., and Gouloub, P.: Aerosol optical depth and Ångström exponent climatology at "El Arenosillo" AERONET site (Huelva, Spain), Q. J. Roy. Meteorol. Soc., 133, 795-807, doi:10.1002/qj.54, 2007b.

Torres, O., Tanskanen, A., Veihelmann, B., Ahn, C., Braak, R., Bhartia, P. K., Veefkind, P., and Levelt P.: Aerosols and surface UV products from Ozone Monitoring Instrument observations: An overview, J. Geophys. Res., 112, D24S47, doi:10.1029/2007JD008809, 2007.

Vilaplana, J. M: Medida y análisis de ozono y de la radiación solar ultravioleta en El Arenosillo-INTA, Ph.D. dissertation, Universidad de Valladolid, Spain, 2004.

Vilaplana, J. M., Cachorro, V. E., Sorbías, M., Luccini, E., de Frutos, A. M., Berjón, A., and de la Morena, B.: Modified calibration procedures for a yankee environmental system UVB-1 biometer based on spectral measurements with a brewer spectrophotometer, Photochem. Photobiol., 82, 508-514, 2006.

Weihs, P., Blumthaler, M., Rieder, H. E., Kreuter, A., Simic, S., Laube, W., Schmalwieser, A. W., Wagner, J. E., and Tanskanen, A.: Measurements of UV irradiance within the area of one satellite pixel, Atmos. Chem. Phys., 8, 5615-5626, doi:10.5194/acp8-5615-2008, 2008.

World Meteorological Organization (WMO): Global ozone research and monitoring project, Tech. Rep. 50, Sci. Assess. of Ozone Depletion, Geneva, Switzerland, 2006 